\title{
Anatomy and Neurophysiology of the Taste System in Aged Animals ${ }^{a}$
}

\author{
CHARLOTTE M. MISTRETTA ${ }^{b}$ \\ Department of Biologic and Materials Sciences \\ School of Dentistry \\ Center for Nursing Research \\ School of Nursing \\ and \\ Center for Human Growth and Development \\ University of Michigan \\ Ann Arbor, Michigan 48109
}

\section{INTRODUCTION}

Although it is generally accepted that sensory system function declines substantially in old mammals, recent literature indicates that the sense of taste might be unique in this regard, at least at the level of the receptor organ and peripheral gustatory innervation. Whereas past studies had reported that taste buds or papillae on the tongue are reduced in number in old humans and mice, the investigations were characterized by various limitations. ${ }^{1,2}$ For example, cadaver material was used without information on medical history to exclude pathology. ${ }^{3-6}$ Taste buds were examined in partial rather than entire papillae. ${ }^{7}$ Taste bud or papilla density was measured in tissue that increased in size with age; obviously, with increasing tissue size, receptor organ density declined, but conclusions were made about loss of taste organs. ${ }^{8}$ In virtually all of the past work, descriptive measures were used to report data and derive conclusions without the application of statistics. ${ }^{3-8}$

More recent studies demonstrate that number and basic structure of taste buds and papillae are well maintained in healthy old animals, and that peripheral taste nerve function is also maintained. These recent investigations are discussed in this chapter. It will be apparent throughout the discussion, however, that studies of age-related differences in the biology of the taste system are limited in scope and number. Such limiting factors place major constraints on the extent to which broad conclusions can be made about the gustatory sense in old animals.

The studies discussed in this paper are based on investigations of taste buds on the tongue. Lingual taste buds are located in three basic papilla types-fungiform, circumvallate, and foliate-and the distribution of these papillae varies across species (FIG. 1). Within each type of gustatory papilla, taste buds are located in a characteristic manner, and some papillae have associated glandular tissue (see

a This work was supported by Grant NS 25825 from the National Institutes of Health.

${ }^{b}$ Address for correspondence: Department of Biologic and Materials Sciences, School of Dentistry, University of Michigan, Ann Arbor, Michigan 48109. 
A

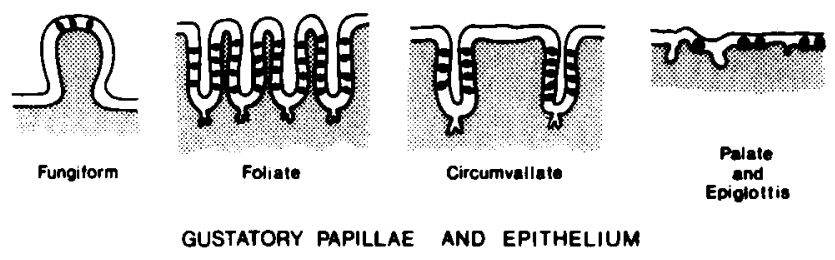

B
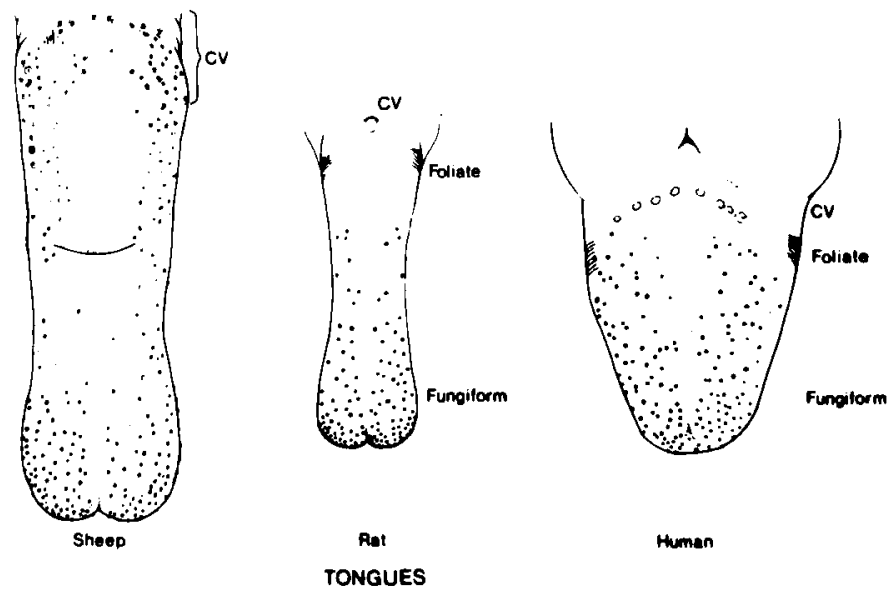

TONGUES

FIGURE 1. (A) Diagram of the types of lingual gustatory papillae, the fungiform, foliate, and circumvallate, and of gustatory epithelium representative of that on the soft palate and epiglottis. (B) Drawings of sheep, rat, and human tongues to illustrate papilla types and distributions. Note that the tongues are not all drawn on the same scale.

Miller $^{9}$ for more detail on these points). Because the differences in distribution and structure of taste buds and papillae are associated with differences in taste function, knowledge of possible changes in all taste organs will be necessary for an eventual, complete picture of the taste system in old age.

\section{STUDIES OF TASTE BUD NUMBER AND ANATOMY IN AGED ANIMALS}

\section{Human}

The first modern study to quantify numbers of taste buds on the tongue of humans across the life cycle focused on examination of buds in fungiform papillae of individuals aged 2 days to 90 years. ${ }^{10}$ Papillae were collected from cadaver tongues within 5 to $12 \mathrm{hr}$ after death caused by traffic accident or sudden cardiac infarction. No tissue was included if there was a medical record of significant 
pathology. Numbers of taste buds per fungiform papilla varied widely, and there was no significant correlation between subject's age and number of taste buds.

More recently, Miller ${ }^{9,11}$ has studied tongues taken at autopsy from subjects aged 22 to 90 years at time of death from acute trauma or acute cardiovascular episode. Fungiform papillae were dissected from specific tongue regions, and all taste buds were counted. Data were expressed in a taste bud density measure for each tongue region. There was no significant decrease in taste bud density with advancing age. The investigator, however, emphasized the extensive variability across subjects for this measure. He concluded that longitudinal studies of taste buds in papillae during an extended period of the life span might be necessary to firmly establish whether there is relation between age and taste bud number.

\section{Rhesus Monkey}

The most comprehensive quantitative studies to determine whether taste buds decrease in old age are those in young and old rhesus monkeys. ${ }^{12,13}$ Tongues obtained at sacrifice from monkeys aged 4 to 31 years were provided by the Aging Monkey Tissue Organ Resource Study of Washington State University. Taste buds were counted in fungiform, circumvallate, and foliate papillae. Thus, these data provide a complete picture of taste buds in all gustatory papilla types on the tongue.

There was no significant difference with age in average number of taste buds in fungiform, circumvallate, or foliate papillae (FIG. 2). Nor did the relative distribution of taste buds on the tongue differ with age; that is, the percentage of taste buds in various types of papillae, relative to total taste buds, remained stable. Finally, taste bud diameter did not differ significantly across age groups for any papilla type.

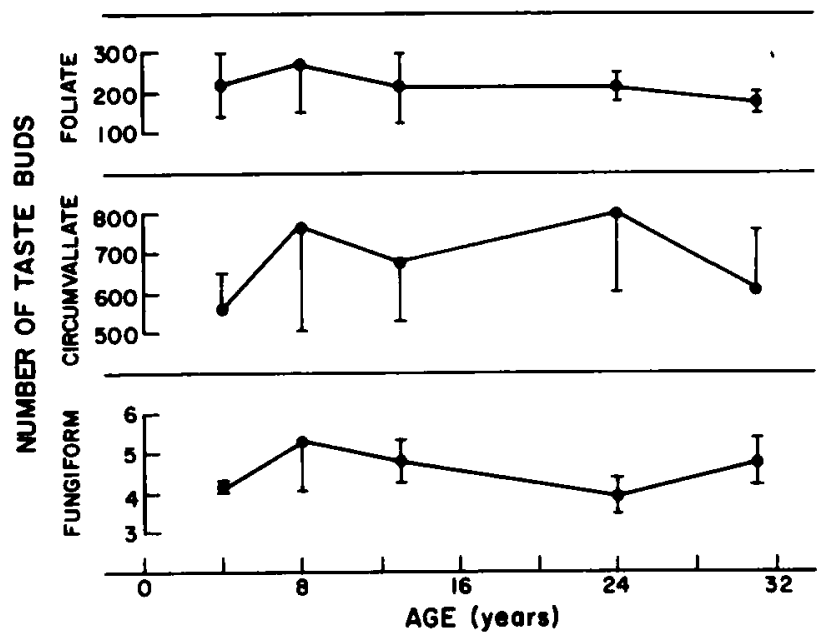

FIGURE 2. Average numbers of taste buds in the fungiform, circumvallate, and foliate papillae of rhesus monkeys in five age groups. Note that data on foliate papillae are for taste buds per papilla cleft. Bars represent standard deviations. There is no significant difference in number of taste buds as a function of age, for any papilla type. From Bradley et al. ${ }^{13}$ 
These data present a remarkable picture of anatomical stability for taste buds on the primate tongue from young adult through very old age. Interestingly, anatomical integrity is maintained even though there is a noticeable alteration in tongue topography in some of these animals. ${ }^{12}$ For example, tongues from five of the six oldest animals, aged 24 to 31 years, had anterior tongue pathology. The tongue tips were scarred or atrophied, and in one monkey the entire tongue was absent anterior to the lingual frenum. The origin of this lingual damage in older monkeys was not obvious, but social interactions or contacts with very cold surfaces when animals were outdoors in the winter could have played some role.

\section{Rat}

Quantitative studies of taste bud number have also been made in old rodents. Taste buds in all fungiform papillae on one half of the tongue and in serial sections of the single circumvallate papilla were counted in tissue from young (5-7 months) and old (23-24 months) Wistar-derived rats. ${ }^{14}$ The animals were from the Gerontology Research Center, National Institute on Aging, Baltimore, and the mean life span of animals in the colony was about 24 months ( $50 \%$ mortality).

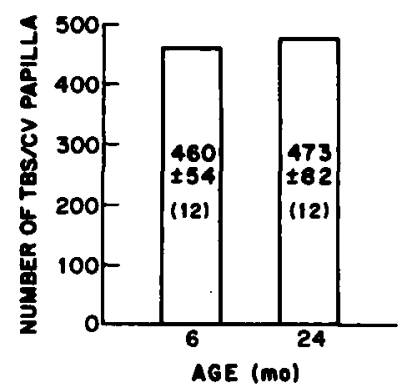

FIGURE 3. Histograms showing the average number of taste buds (TBS) in the circumvallate (CV) papilla of young (6 months) and old (24 months) Wistar rats. A mean and standard deviation is noted within each bar, and the number of animals per age group is in parentheses. There is no difference in taste bud number between the two age groups. From Mistretta and Baum. ${ }^{14}$

Average numbers of taste buds in circumvallate papillae from the young and old age groups were 460 and 473 , respectively (FIG. 3). Thus, there was no decrease in taste buds with age, and no significant difference in taste bud diameter. Furthermore, at the light microscopic level, taste buds were morphologically similar (Frg. 4).

Taste buds were also maintained in fungiform papillae. The rat typically has one taste bud per fungiform papilla. In young rats, $99 \%$ of all papillae had a taste bud-in old rats, $98 \%$. At the light microscopic level, there was no evidence of structural deterioration of the taste buds (FIG. 5). Animals from this same colony had significant changes in various characteristics of the submandibular salivary gland by 23 to 24 months, ${ }^{15}$ so the rats were not free from age-related biological differences in the oral cavity.

Taste buds in fungiform papillae have been counted in Fischer 344 rats. The rats in this strain were aged 4 to 6 months, 20 to 24 months, and 30 to 37 months, and were obtained through the National Institute on Aging. ${ }^{16}$ All papillae on onehalf of the anterior tongue were examined in serial sections; the presence or absence of a taste bud for each papilla was noted; and each taste bud found had its diameter measured. Average percentages of papillae that contained a taste bud 


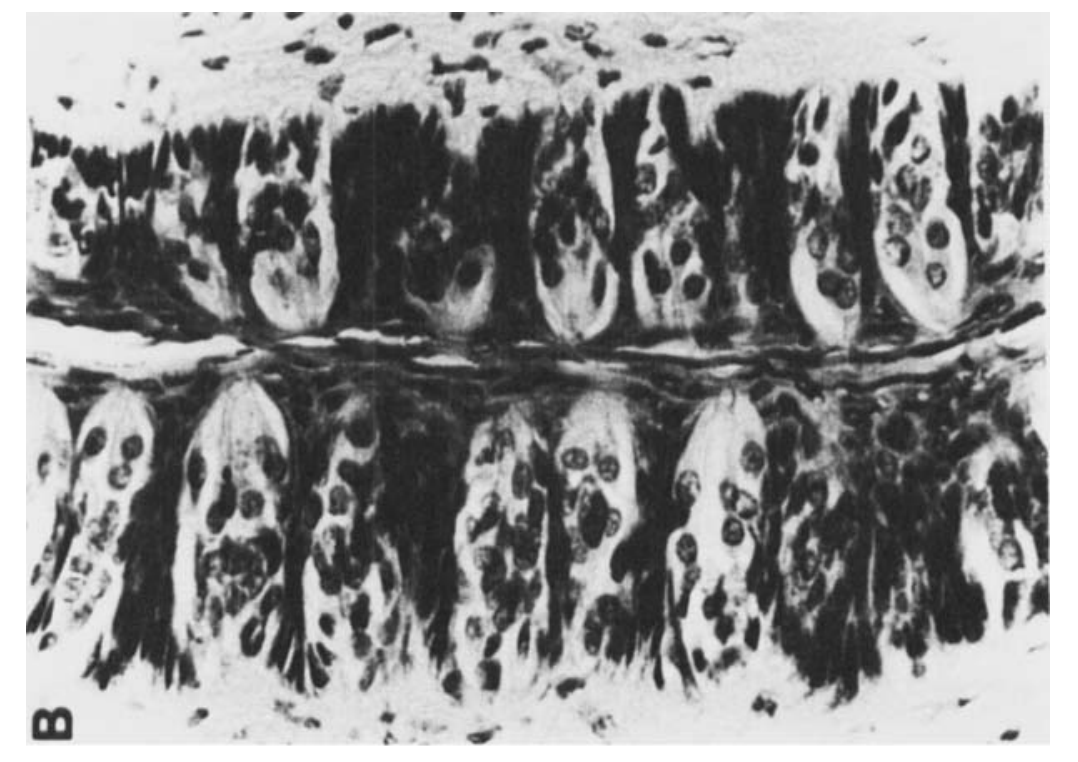

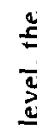
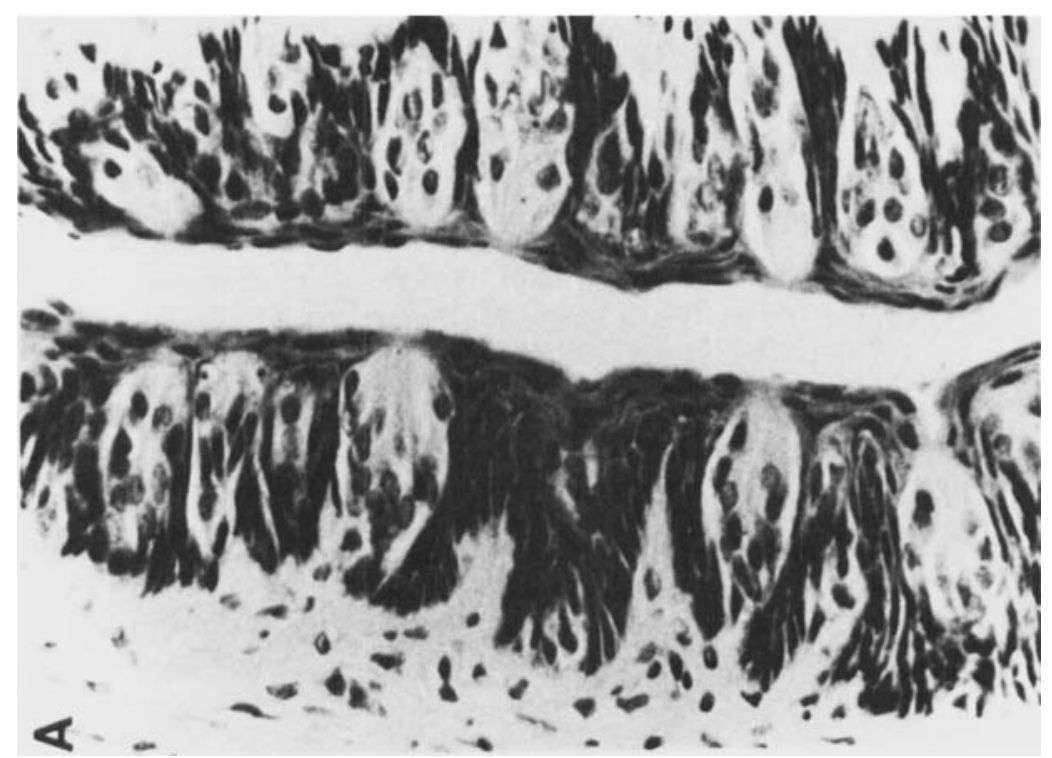

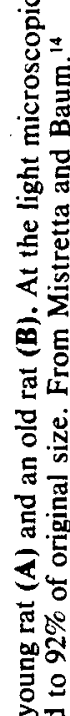

渮

홀

홍

$\cong x$

昰

E

는

只

도뮤

눙

要

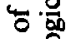

등응

옹응

.

魚

它

ล.

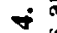

뽀ำ

它 


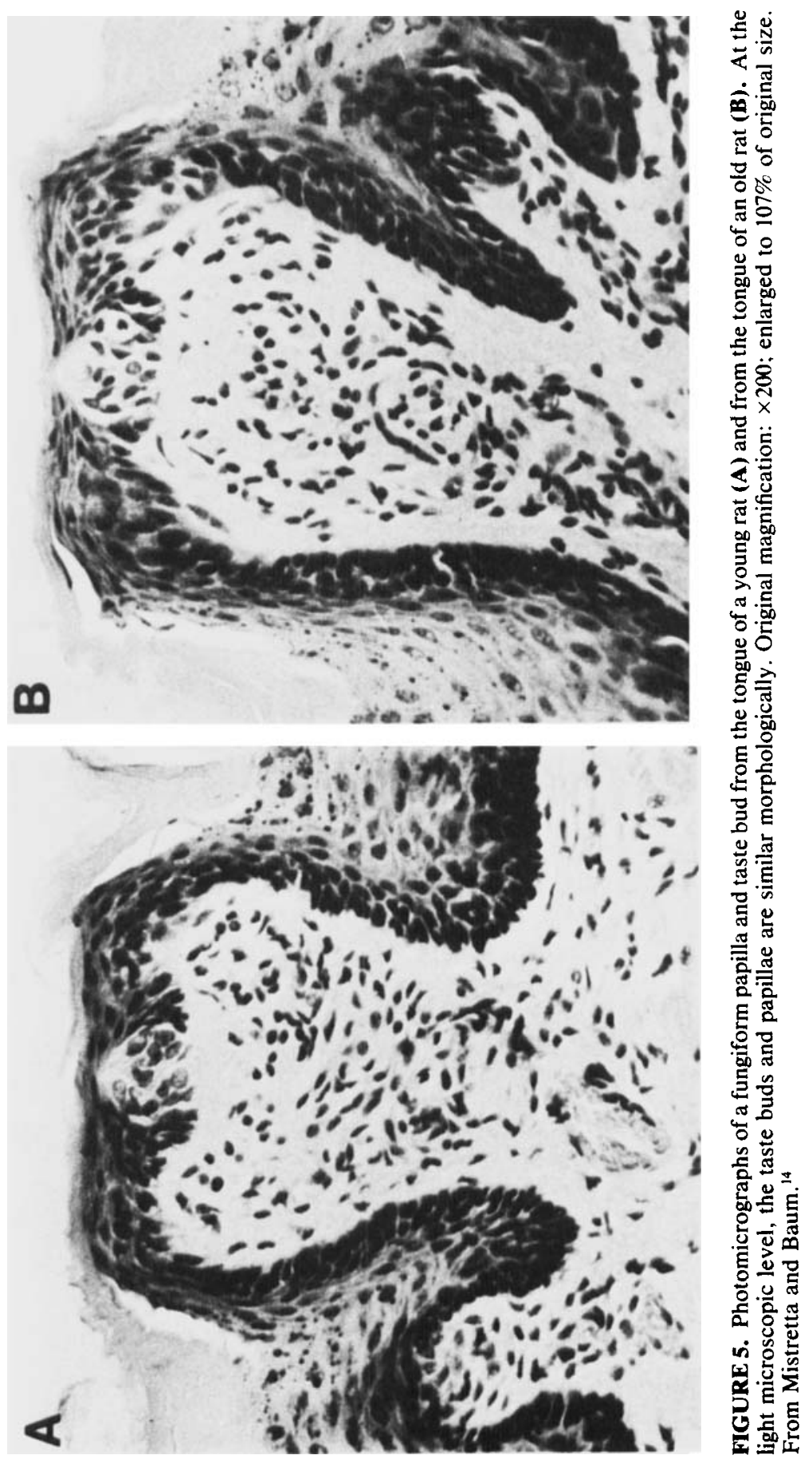


were $99.6,99.3$, and $94.7 \%$ in the three age groups. This is a significant age-related difference, but the actual number of taste buds lost in the oldest rats was small. The maximum loss in any animal was 18 out of about 180 taste buds. It has been demonstrated that denervation and degeneration of major populations of lingual taste buds do not affect behavioral, taste preference/aversion functions in rats. ${ }^{17}$ Therefore, one would not predict profound behavioral deficits in rats missing 18 or fewer taste buds.

The locations of papillae without taste buds were not confined to any one tongue area, but were most numerous in areas of greatest taste bud density, as would be expected. Thus, the decrease in taste bud number did not alter the usual distribution of lingual taste buds. Taste bud diameter did not differ with age, and general anatomical characteristics of buds were similar in all groups.

In summary, the recent literature on quantitative studies of tongue taste buds in rats, monkeys, and humans presents converging evidence that the receptor organ of taste bud and papilla is maintained in number, distribution, and structure during the process of aging.

\section{STUDIES OF NEUROPHYSIOLOGICAL TASTE FUNCTION IN OLD RATS}

To determine whether taste bud function is maintained in old rats, electrophysiological recordings were made from the chorda tympani nerve, which innervates taste buds in fungiform papillae on the anterior tongue. ${ }^{18}$ Male and female Fischer 344 rats aged 5 to 7,23 to 25 , and 29 to 32 months were studied, and these groups were designated 6,24 , and 30 months, respectively. Taste stimuli included a series of $0.1 \mathrm{M}$ salts $\left(\mathrm{NaCl}, \mathrm{LiCl}, \mathrm{NH}_{4} \mathrm{Cl}, \mathrm{KCl}, \mathrm{MgCl}_{2}\right)$, two acids $(0.025 \mathrm{M}$ citric acid, $0.01 \mathrm{~N} \mathrm{HCl}$ ), $1.0 \mathrm{M}$ sucrose, and $0.04 \mathrm{M}$ quinine hydrochloride. A concentration series of each salt $(0.025$ to $0.75 \mathrm{M})$ was also used.

Neural activity was recorded from the whole chorda tympani nerve while chemical stimuli were flowed over the tongue. Summated activity was displayed on a pen recorder, and the height of the pen deflection was used as a measure of neural response magnitude. Absolute response magnitudes were normalized by calculating ratios of the response to each chemical relative to the response to 0.1 $\mathrm{M} \mathrm{NaCl}$. Use of $\mathrm{NaCl}$ as the standard for calculating ratios allowed comparison with other published response ratios for adult rats.

Across all age groups, taste responses to five salts, two acids, sucrose, and quinine hydrochloride were maintained at substantial magnitudes (FIG. 6). Taste responses to some of these chemicals, however, differed statistically with age. Relative to $\mathrm{NaCl}$, responses to $\mathrm{NH}_{4} \mathrm{Cl}$ increased and those to $\mathrm{MgCl}_{2}$ decreased. Relative responses for citric acid decreased with age, and those for sucrose increased. Response ratios for $\mathrm{HCl}$ differed when data for either sex were analyzed separately. Response ratios for $\mathrm{LiCl}, \mathrm{KCl}$, and quinine hydrochloride did not differ with age.

Although the age-related differences in response ratios for $\mathrm{NH}_{4} \mathrm{Cl}, \mathrm{MgCl}_{2}$, sucrose, citric acid, and $\mathrm{HCl}$ were statistically significant, they were not very large. The largest difference was that observed for sucrose ratios, which nearly doubled between 6 and 30 months (FIG. 7). Therefore, it seems that the peripheral taste system functions well in old rats, and that the differences in taste responses are not large.

Examination of responses to a range of concentrations for the five salts also demonstrated that taste function is maintained in old age. There were no signifi- 

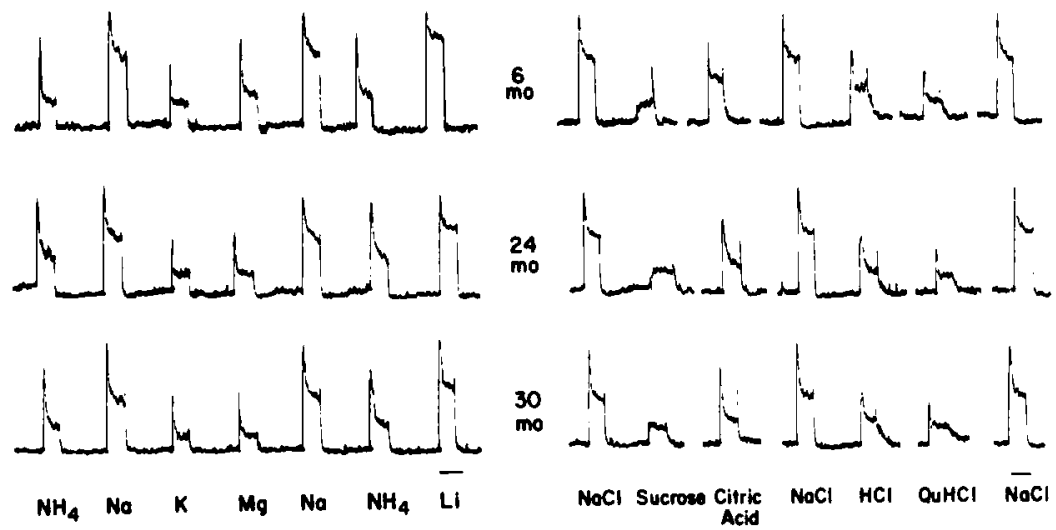

FIGURE 6. Summated records of neural responses from the chorda tympani in Fischer 344 rats from each of three age groups. Chemical stimuli were $0.1 \mathrm{M} \mathrm{NH}_{4} \mathrm{Cl}, \mathrm{NaCl}, \mathrm{KCl}, \mathrm{MgCl}_{2}$, and $\mathrm{LiCl} ; 1.0 \mathrm{M}$ sucrose; $0.025 \mathrm{M}$ citric acid; $0.01 \mathrm{~N} \mathrm{HCl}$; and $0.04 \mathrm{M}$ quinine hydrochloride. The stimuli were applied to the anterior tongue in the order indicated on the figure. The time bar under the last response in each panel represents $30 \mathrm{sec}$. Breaks appear in the continuous records where rinse periods exceeded 2 min. From McBride and Mistretta. ${ }^{18}$
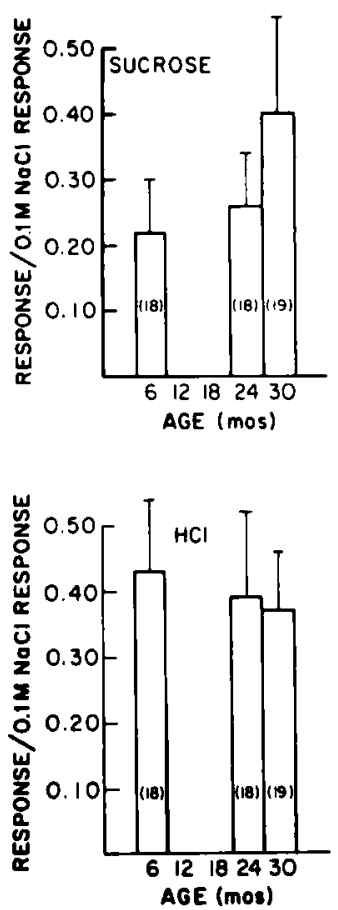

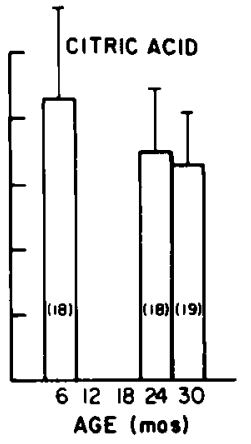

OUININE HCI

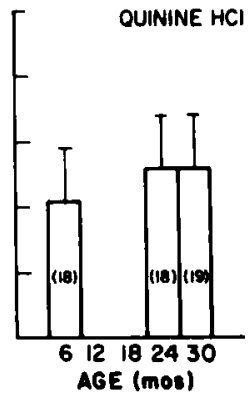

FIGURE 7. Ratios of chorda tympani nerve responses to sucrose, citric acid, hydrochloric acid, and quinine hydrochloride, relative to the response for $\mathrm{NaCl}$, for all rats in three age groups. Means and standard deviations are plotted. Numbers of animals in each group are given in parentheses within the histogram bars. From McBride and Mistretta. ${ }^{18}$ 
cant differences in the shapes of the response/concentration functions for $\mathrm{NH}_{4} \mathrm{Cl}$, $\mathrm{KCl}, \mathrm{MgCl}_{2}$, or $\mathrm{LiCl}$ (FIG. 8). Functions for $\mathrm{NaCl}$ were significantly different, however, because the curve for responses in the 6-month rats was steeper than the curves in $24-$ or 30 -month animals. These data suggest that the small, but
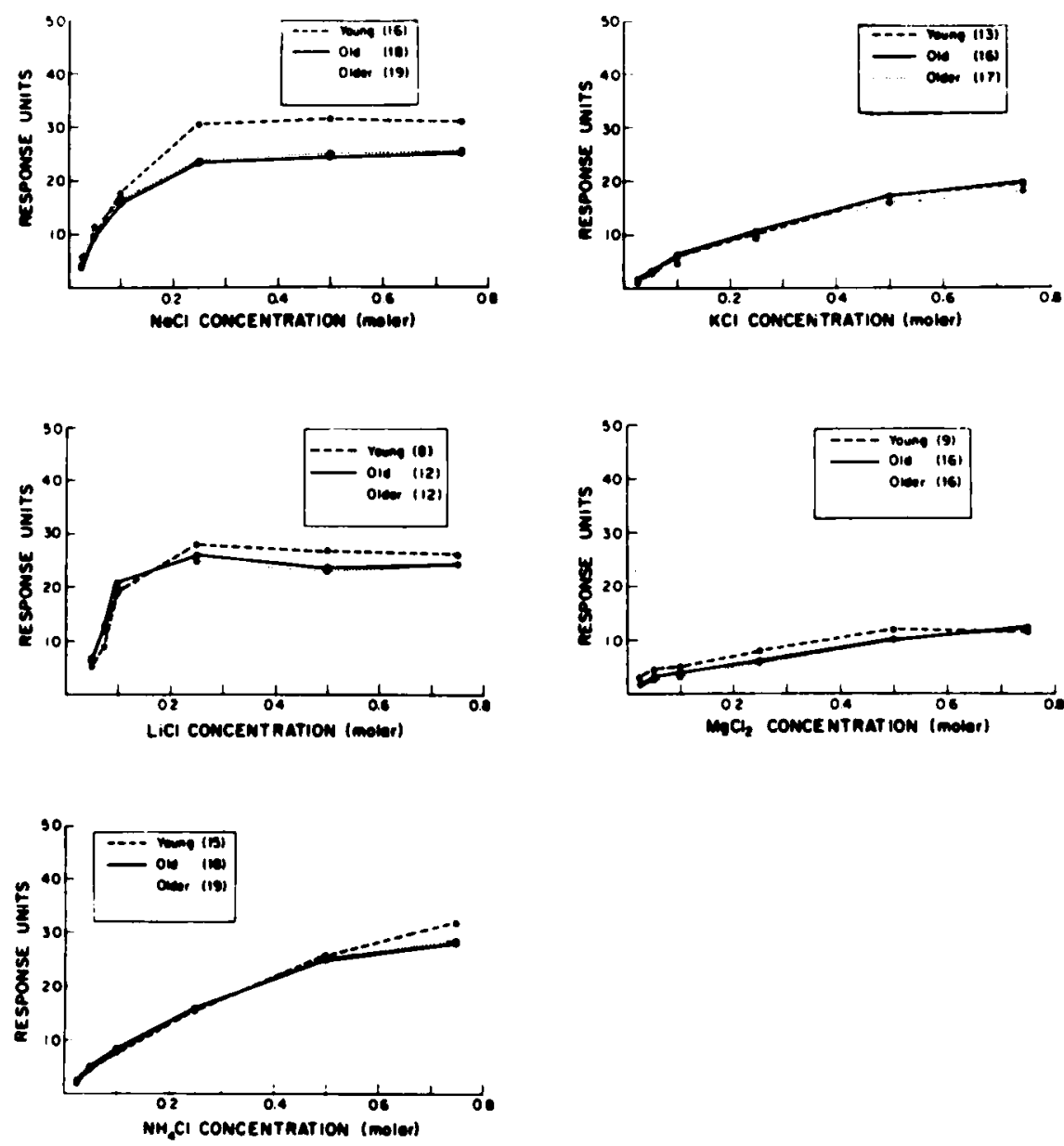

FIGURE 8. Average responses to concentration series of $\mathrm{NaCl}, \mathrm{LiCl}, \mathrm{NH}_{4} \mathrm{Cl}, \mathrm{KCl}$, and $\mathrm{MgCl}_{2}$ in rats from each of three age groups. The number of rats at each age is noted in parentheses in the legends. Absolute response units are used in the graphs because the comparison is among shapes of the response/concentration curves at different ages, not among response magnitudes. From McBride and Mistretta. ${ }^{18}$

significant, differences in response ratios for various chemicals might derive from differences in responses to the standard chemical, $\mathrm{NaCl}$, with age.

To learn whether responses to $\mathrm{NaCl}$ in fact decrease with age, it will be necessary to conduct a study of responses from single chorda tympani nerve fibers. Data on responses from single fibers can demonstrate whether there is a 
decreased response frequency to $\mathrm{NaCl}$, a decrease in proportion of fibers that respond well to $\mathrm{NaCl}$, or both. For initial studies on the taste system in old animals, however, it was important to use whole-nerve recordings to record responses from the innervation to a large population of taste buds and learn about general response parameters of the system.
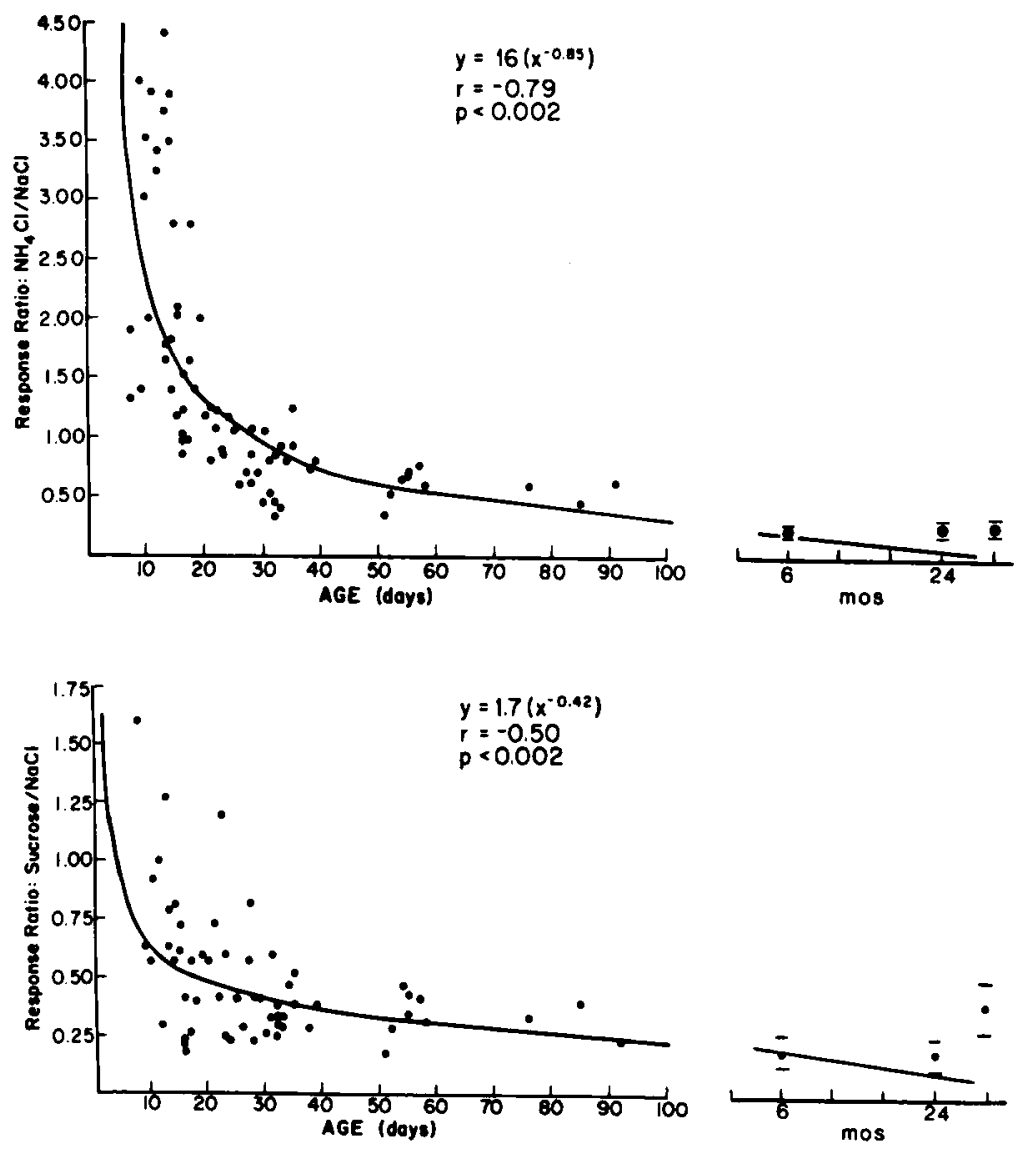

FIGURE 9. Ratios of responses to $\mathrm{NH}_{4} \mathrm{Cl}$ and sucrose, relative to the response for $\mathrm{NaCl}$, in rats from 7 days through 30 months of age. The decline in early response ratios was fit by a power function for each chemical; the line describing this function has been extended to $\mathbf{3 0}$ months. The declining function for response ratios that describes early development, however, actually increases over adult to old ages. Note the magnitude of the age-related differences in early development compared with the magnitude of those in old age. From McBride and Mistretta. ${ }^{18}$

Additional perspective on the magnitude of the age-related neurophysiological differences in Fischer 344 taste responses can be gained by comparing data on old rats with data on young, developing rats (FIG. 9). During early development, the response to $\mathrm{NaCl}$ increases relative to the $\mathrm{NH}_{4} \mathrm{Cl}$ response. Therefore, $\mathrm{NH}_{4} \mathrm{Cl}$ / 
$\mathrm{NaCl}$ response ratios decrease. Note that this change is opposite in direction from that observed in old Fischer rats. The magnitude of differences in early development compared with the magnitude of those in old age is striking. For example, although $\mathrm{NH}_{4} \mathrm{Cl} / \mathrm{NaCl}$ ratios decreased by more than $450 \%$ from 7 to 50 days (postnatal), they increased by only $19 \%$ between 6 and 30 months.

\section{SUMMARY AND CONCLUSIONS}

In summary, the recent data from quantitative studies of taste buds in old humans, rhesus monkeys, and rats complement neurophysiological data on taste responses from aged rats and lead to the general conclusion that the peripheral taste system is maintained structurally and functionally across the life span. Although some statistically significant differences were observed, the magnitude of these differences would not lead one to predict altered taste preferences or feeding behavior in old animals.

The robust nature of the peripheral sense of taste in old age appears to be in sharp contrast to other sensory systems. Not only do receptors alter with age, but accessory organs, such as the lens in the visual system, also alter structurally so that sensory function is compromised. One factor contributing to maintenance of the receptor organ of taste bud and papilla is the turnover and replacement of taste bud cells and surrounding epithelial cells. ${ }^{19}$ Recent studies in aged mice indicate no differences in turnover time in epithelial mucosa lining the mouth. ${ }^{20}$ There are no data on turnover time, however, for taste bud cells or for gustatory papilla epithelium in old animals. Alterations in taste bud cell or membrane receptor turnover could affect function.

In other cell types and receptors, age-related differences in membrane lipids, proteins, and fluidity characteristics are reported. ${ }^{21}$ Membrane changes such as these are proposed to account for age-related differences in response properties of the system of cardiac muscarinic receptors, ${ }^{22}$ a system in which density of receptors does not alter. The small, but statistically significant, differences in neurophysiological responses to taste stimuli from the chorda tympani nerve might well relate to age-related differences in membrane receptors.

Not only is there an absence of data on turnover time or membrane characteristics for taste bud cells in old age, but there are no observations on the ultrastructure of taste buds in old animals. The taste bud is a complex structure, composed of many cells and different cell types, with a specific orientation and access to the oral cavity via the taste pore, and with extensive associations with the innervating afferent fibers (FIG. 10). Ultrastructural observations could provide information on changes in synapses and other nerve/cell contacts-in microvilli and taste pore structure, and in numbers of various cell types within the bud. Such data will be essential to understanding the nature and extent of age-related alterations in the taste system.

Furthermore, it is important to remember that all observations on the biology of the aging taste system have been made on lingual taste buds. There is an extensive literature about the structure and function of taste buds on the epiglottis ${ }^{23-28}$ and about the neurophysiological responses from taste buds on the soft palate of rat. ${ }^{29}$ Yet there are no publications about taste buds on the soft palate or epiglottis in aged animals. Because taste buds in different regions are innervated by various branches of three different cranial nerves, it is necessary to survey taste buds throughout the oral/pharyngeal complex to have a complete perspective on possible age-related differences. 
It is possible, however, even with all of the caveats discussed above, to make some general statements about the peripheral taste system and aging. Although there may be as yet undiscovered changes in cell membranes, biochemistry, or ultrastructure within the taste bud, there is no evidence of gross degenerative change in taste buds on the tongues of old humans, monkeys, or rats. Taste buds innervated by the chorda tympani and glossopharyngeal nerves are maintained in old age at numbers comparable to those in young animals. As might be expected from evidence of taste bud maintenance, there are only small changes in neurophysiological taste responses to chemicals on the tongue. Neural responses to various chemicals and to a wide range of concentrations are maintained in old rats.

The taste bud and papilla are parts of a sensory organ that must continually confront a range of materials in the oral cavity, some of which are very abrasive,

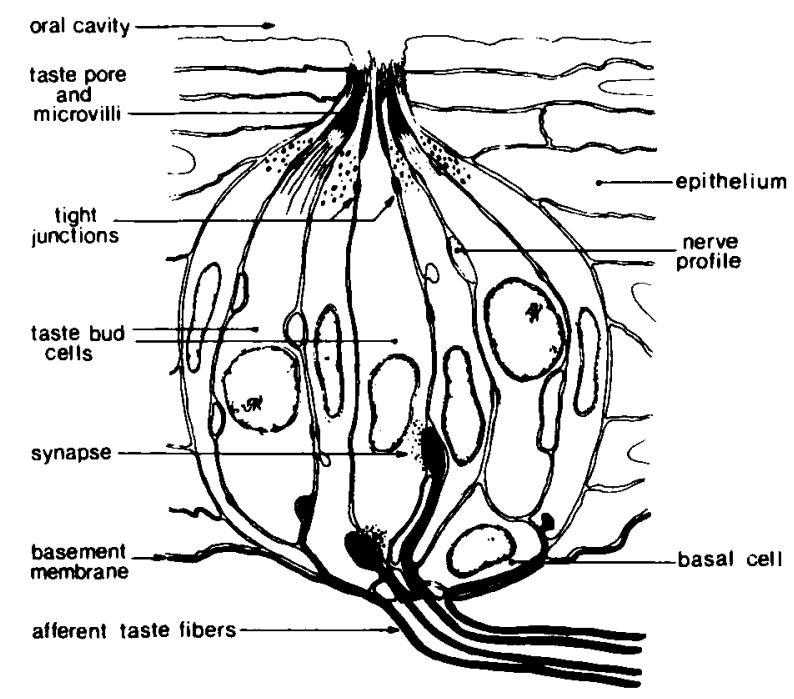

FIGURE 10. Representation of the taste bud and associated structures.

and a range of chemicals, including some with irritant properties. Concentrations of salts and acids that would kill other cells are effective taste stimuli for taste buds, and the taste receptor response recovers immediately when chemicals are removed by rinsing or salivation. The robust nature of taste buds may stand these receptors in good stead during the aging process.

If there are no substantial changes in peripheral structure and function of the taste system, why are there observed differences in behavioral and psychophysical responses? To the extent that the latter differences occur, they might reflect alterations in the central taste system. Again, there is a large gap in the field because there have been no studies to discern possible age-related differences in structure and function of taste areas in the medulla, pons, thalamus, or cortex.

Clearly, we have only the most rudimentary knowledge of the neurobiology of the sense of taste in old animals. Our understanding of the extent to which the 
gustatory sense truly is unique in its apparent resistance to deleterious effects of the aging process awaits substantial additions to the literature.

\section{REFERENCES}

1. Mistretta, C. M. 1984. Aging effects on anatomy and neurophysiology of taste and smell. Gerodontology 3: 131-136.

2. MistrettA, C. M. 1986. Taste anatomy and neurophysiology in early development and old age. In Clinical Measurements of Taste and Smell. H. L. Meiselman \& R. S. Rivlin, Eds.: 283-304. Macmillan. New York, NY.

3. Arey, L. B., M. J. Tremaine \& F. L. Monzingo. 1935. The numerical and topographical relations of taste buds to human circumvallate papillae throughout the life span. Anat. Rec. 64: 9-25.

4. MochizUKI, Y. 1937. An observation on the numerical and topographical relations of taste buds to circumvallate papillae of Japanese. Okajimas Folia Anat. Jpn. 15: 595608.

5. Mochizukı, Y. 1939. Studies on the papillae foliata of Japanese. 1. The number of papillae foliata. Okajimas Folia Anat. Jpn. 18: 337-354.

6. MochIZUKI, Y. 1939. Studies on the papillae foliata of Japanese. 2. The number of taste buds. Okajimas Folia Anat. Jpn. 18: 355-369.

7. Conger, A. D. \& M. A. Wells. 1969. Radiation and aging effect on taste structure and function. Radiat. Res. 37: 31-49.

8. Moses, S. W., Y. Rotem, N. Jagoda, N. Talmor, F. EichHorn \& S. Levin, 1967. A clinical, genetic and biochemical study of familial dysautonomia in Israel. Isr. J. Med. Sci. 3: 358-371.

9. Miller, I. J., JR. 1989. Variation in human taste bud density as a function of age. Ann. N.Y. Acad. Sci. This volume.

10. ARVIDSON, K. 1979. Location and variation in number of taste buds in human fungiform papillae. Scand. J. Dent. Res. 87: 435-442.

11. Miller, I. J., JR. 1988. Human taste bud density across adult age groups. J. Gerontol. 43: B26-B30.

12. Bradley, R. M., H. M. Stedman \& C. M. Mistretta. 1985. A quantitative study of lingual taste buds and papillae in the aging rhesus monkey tongue. In Behavior and Pathology of Aging in Rhesus Monkeys. R. T. Davis \& C. W. Leathers, Eds.: 187199. Alan R. Liss. New York, NY.

13. Bradley, R. M., H. M. Stedman \& C. M. Mistretta. 1985. Age does not affect numbers of taste buds and papillae in adult rhesus monkeys. Anat. Rec. 212: 246249.

14. Mistretta, C. M. \& B. J. Baum. 1984. Quantitative study of taste buds in fungiform and circumvallate papillae of young and aged rats. J. Anat. 138: 323-332.

15. KUYATt, B. L. \& B. J. BAUM. 1981. Characteristics of submandibular glands from young and aged rats. J. Dent. Res. 60: 936-941.

16. Mistretta, C. M. \& I. A. OAKLeY. 1986. Quantitative anatomical study of taste buds in fungiform papillae of young and old Fischer rats. J. Gerontol. 41: 315-318.

17. PfaffmanN, C. 1952. Taste preference and aversion following lingual denervation. J. Comp. Physiol. Psychol. 45: 393-400.

18. MCBride, M. R. \& C. M. Mistretta. 1986. Taste responses from the chorda tympani nerve in young and old Fischer rats. J. Gerontol. 41: 306-314.

19. Beidler, L. M. \& R. L. Smallman. 1965. Renewal of cells within taste buds. J. Cell. Biol. 27: 263-272.

20. HiLt, M. W. 1984. Influence of aging on skin and oral mucosa. Gerodontology 3: $35-45$.

21. Hochstein, P. \& S. K. Jain. 1981. Association of lipid peroxidation and polymerization of membrane proteins with erythrocyte aging. Fed. Proc. 40: 183-188.

22. Baker, S. P., S. Marchand, E. O'Neil, C. A. Nelson \& P. Posner. 1985. Agerelated changes in cardiac muscarinic receptors: Decreased ability of the receptor to form a high-affinity agonist binding state. J. Gerontol. 40: 141-146. 
23. Bradley, R. M., M. L. Cheal \& Y. H. Kim. 1980. Quantitative analysis of developing epiglottal taste buds in sheep. J. Anat. 130: 25-32.

24. Bradley, R. M. 1982. The role of epiglottal and lingual chemoreceptors: A comparison. In Determination of Behaviour by Chemical Stimuli. J. E. Steiner \& J. R. Ganchrow, Eds.: 37-45. IRL Press. London.

25. Stedman, H. M., R. M. Bradley, C. M. Mistretta \& B. E. Bradley. 1980. Chemosensitive responses from the cat epiglottis. Chem. Senses 5: 233-245.

26. Stedman, H. M., C. M. Mistretta \& R. M. Bradley. 1983. A quantitative study of cat epiglottal taste buds during development. J. Anat. 136: 821-827.

27. Bradley, R. M., H. M. Stedman \& C. M. Mistretta. 1983. Superior laryngeal nerve response patterns to chemical stimulation of sheep epiglottis. Brain Res. 276: 81-93.

28. Sweazey, R. D. \& R. M. Bradley. 1988. Response of lamb nucleus of the solitary tract neurons to chemical stimulation of the epiglottis. Brain Res. 439: 195-210.

29. Nejad, M. S. 1986. The neural activities of the greater superficial petrosal nerve of the rat in response to chemical stimulation of the palate. Chem. Senses 11: 283-293. 